\title{
Effects of low temperatures on Chilocorus kuwanae (Coleoptera: Coccinellidae) trophic activity
}

\author{
CARlo RICCI ${ }^{1}$, Andrea PRIMAVERA ${ }^{1}$ and VAleria NEGRI ${ }^{2}$ \\ ${ }^{1}$ Department of Agricultural and Environmental Sciences, Perugia University, Borgo XX Giugno, 06100 Perugia, Italy; \\ e-mail: cricci@unipg.it \\ ${ }^{2}$ Department of Biology and Agro-environmental Biotechnology, Perugia University, Borgo XX Giugno, 06100 Perugia, Italy
}

Key words. Coccinellidae, Chilocorus kuwanae, Unaspis euonymi, coccidophagous predator, low temperatures, Euonymus japonicus, Diaspididae, feeding behaviour

\begin{abstract}
Chilocorus kuwanae Silvestri is an effective predator of Unaspis euonymi (Comstock), a scale insect harmful to spindle trees (Euonymus europeus L. and E. japonicus Thumb). The feeding behaviour was studied on wild adults, collected from spindle trees in the Botanic Garden of Perugia University, and fed on overwintering U. euonymi females. The insects were exposed to gradually changing constant temperatures $\left(13^{\circ} \rightarrow 10^{\circ} \rightarrow 8^{\circ} \rightarrow 6^{\circ} \rightarrow 4^{\circ} \rightarrow 2^{\circ} \rightarrow 13^{\circ} \rightarrow 15^{\circ} \mathrm{C}\right)$ for a ten day period at each temperature. $C$. kuwanae adults preyed on the scale also at low temperatures. The number of scales eaten decreased with decreasing temperatures from the initial $13^{\circ} \mathrm{C}$ to $4{ }^{\circ} \mathrm{C}$, and at $2^{\circ} \mathrm{C}$ the trophic activity of $C$. kuwanae adults almost stopped although they made brief walks in the petri dishes. At all tested temperatures the ladybirds made holes in or lifted the scale cover and preyed on the female. Sometimes they lifted the scale cover, but did not prey on these U. euonymi females which were destined to die from cold. As the temperature dropped from $13^{\circ} \mathrm{C}$ to $4^{\circ} \mathrm{C}$, the number of females eaten by ladybird males and females did not differ statistically. When the temperature was raised to $13^{\circ} \mathrm{C}$ and $15^{\circ} \mathrm{C}$, the ladybirds resumed feeding. Large differences were recorded between sexes, with females showing a much higher feeding activity than males. Scale cover lifting was most frequent at the beginning of the experiment and then decreased with diminishing temperatures, although no significant difference was recorded among temperatures within the range from $10^{\circ} \mathrm{C}$ to $4{ }^{\circ} \mathrm{C}$. The threshold for trophic activity can be taken as $2^{\circ} \mathrm{C}$ since we noted that a few $(12 \%)$ individuals on one day showed predatory activity. At $13^{\circ} \mathrm{C}$ and $15^{\circ} \mathrm{C}$ lifting activity rose again but remained at a lower level than at the initial exposure to $13^{\circ} \mathrm{C}$. There was no significant difference in activity at 13 and $15^{\circ} \mathrm{C}$ upon raising the temperature. As for total number of $U$. euonymi damaged by $C$. kuwanae the trend in damage revealed the same pattern as for number of scales eaten. At the final exposure to $15^{\circ} \mathrm{C}$, $60 \%$ of $C$. kuwanae females laid eggs. Our data demonstrate that $C$. kuwanae can reduce $U$. euonymi populations in a submediterranean environment even in winter when the range of temperatures is similar to that tested in this experiment.
\end{abstract}

\section{INTRODUCTION}

Chilocorus kuwanae Silvestri is a coccinellid of the Far East (Kato, 1968; Xia et al., 1986; Kuznetsov, 1987). It is an effective predator of various scale insects, both in urban areas and in agroecosystems. In China Unaspis euonymi Comstock and Ceroplastes japonicus Green are essential preys for C. kuwanae (Xia et al., 1986). These two scales are also present in the mediterranean area. $U$. euonymi infests Euonymus europeus L. (a wild spindle) and E. japonicus L. (used as ornamental hedges in gardens), and C. japonicus infests various urban (e.g. Laurus nobilis) and cultivated plants (e.g. Pirus communis). In the case of heavy outbreaks of $U$. euonymi some spindle plants can be destroyed (Brewer \& Olivier, 1987; Drea \& Carlson, 1987; Primavera \& Ricci, 1994; Driesche et al., 1998b), often with substantial economic cost (Jefferson \& Schultz, 1995). It has been noted that the incidence of its natural enemies is rather low, so C. kuwanae has been introduced into various countries (e.g. USA, France, Israel, Italy) for biological control of U. euonymi with various outcomes (Benassy, 1977; Drea \& Carlson, 1987; Hendrickson et al., 1991; Ricci et al., 1991; Nalepa et al., 1993; Jefferson et al., 1995; Lambdin, 1995; Driesche et al., 1998a; Driesche \& Nunn, 2003). In Central Italy $C$. kuwanae was established at some release sites, and the species was observed to spread to other habitats on wild spindle and E. japonicus hedges (Primavera \& Ricci, 1994). After 14 years the ladybird is still present in different urban habitats (Ricci et al., unpubl.). According to Nohara (1962) this ladybird overwinters in protected sites and resumes its activity at the onset of mild spring weather characterized by temperatures over $10^{\circ} \mathrm{C}$. Drea \& Carlson (1987) reported that in eastern USA C. kuwanae was active even in January if the temperature rose above $10^{\circ} \mathrm{C}$. Also in Central Italy we found this ladybird in the E. japonicus hedges on colonies of $U$. euonymi on sunny winter days (Primavera \& Ricci, 1994). However, there is no record of its predatory activity. Podoler \& Henen (1983), studying the effects of the temperature $\left(20^{\circ}\right.$ to $30^{\circ} \mathrm{C}$ ) noted that the activity decreased with increases in temperature within this range.

The aims of this research were (1) to determine if $C$. kuwanae adults preyed at low temperatures on overwintering $U$. euonymi females infesting E. japonicus plants, (2) to find out the temperature threshold of feeding activity, (3) to study the feeding behaviour of the coccinellid and (4) to find out the number of overwintering females damaged. 


\section{MATERIAL AND METHODS}

The effect of constant low temperatures on the trophic activity of $C$. kuwanae adults was studied by placing these adults with overwintering $U$. euonymi females in a climatic chamber (12L : 12D, R.H. $75 \pm 5 \%, 3000$ Lux).

On 27 November 2001 (a bright sunny day) about 4.00 p.m., 100 coccinellid adults were randomly collected from a hedge in the Botanic Garden of Perugia University. A random sample collected in the wild was preferred to a sample bred in the laboratory in order to study insects which were affected and selected by the natural environment. At the collection site the maximum air temperature was $11^{\circ} \mathrm{C}$ at 2.00 p.m., whereas the temperature on the trunks of E. japonicus plants, where the adults were present, was $13^{\circ} \mathrm{C}$.

In the laboratory we isolated males and females and then randomly took 25 individuals per sex for the study. The insects were confined in petri dishes $(\varnothing 10 \mathrm{~cm})$ where the cover had a nylon window and the bottom was lined with a disk of blotting paper.

To feed the insects, fifty E. japonicus leaves, infested with overwintering $U$. euonymus females, were collected in the field every day from spindle trees protected from natural enemies by nylon nets. Under the stereomicroscope each leaf was cleaned of male wax cover remains and damaged females, leaving the living overwintering females (minimum of 15 on each leaf). The prey on each single leaf were counted. The leaf stalk was then inserted into a glass microtube containing water and stoppered with cotton wool to allow the coccinellid adults to drink. Every microtube was fixed horizontally at the centre of the blotting paper in the petri dish.

One coccinellid was put into each prepared petri dish. The 50 petri dishes were randomly arranged on the middle shelf of the chamber and every day the position was changed, so that each adult had the same total amount of light over the experimental period (the fluorescent tubes are on the chamber side-walls).

The growth chamber temperature was initially set at $13^{\circ} \mathrm{C}$ which was the temperature found on the trunks when adults were collected, and this temperature was maintained for 10 days. After this first period of 10 days at $13^{\circ} \mathrm{C}$, the temperature was lowered gradually over $12 \mathrm{~h}$ to $10^{\circ} \mathrm{C}$. This was repeated several times at progressively lower temperatures $\left(8^{\circ}, 6^{\circ}, 4^{\circ}\right.$, $2^{\circ} \mathrm{C}$ ) so that each temperature was experienced for 10 days. Previous field observations about insect movements in winter showed that $C$. kuwanae is active also when the temperature variation during the day is much higher than that imposed in the experimental conditions (e.g. -6 to $+14^{\circ} \mathrm{C}$ trunk temperatures) and Chilocorus does not suffer from this variation (Ricci et al., unpubl. data). Therefore at the end of the $2{ }^{\circ} \mathrm{C}$ period the tem- perature was increased gradually to $13^{\circ} \mathrm{C}$ over $12 \mathrm{~h}$ and then kept constant at $13^{\circ} \mathrm{C}$ for another 10 days. Finally, the temperature was raised to $15^{\circ} \mathrm{C}$ for another 10 days. The study lasted 80 days.

The leaves infested by the known number of $U$. euonymi females were substituted every day one hour before switching off the light. The removed leaves were examined under a stereomicroscope and the damaged females counted.

Previous observations showed that $C$. kuwanae adults had two eating modalities, making a hole in the female scale cover or lifting the scale cover and feeding on the exposed female. However, they sometimes lifted the scale cover, but did not feed on the prey. This would also result in the death of the prey because in natural habitats scale insects without cover will die from cold when exposed to low temperatures (below $0^{\circ} \mathrm{C}$ ).

The following data were recorded each day for each of the controlled temperatures across the experiment:

1. number of holed and eaten scales;

2. number of lifted and eaten scales;

3. number of lifted but not eaten scales;

4. total number of eaten scales $(1+2)$;

5 . total number of damaged scales $(1+2+3)$. This last point represents the most significant indicator of $C$. kuwanae predatory activity, since lifting scales, a display of predatory intention, is included in it.

At $13^{\circ}$ and $15^{\circ} \mathrm{C}$ we also checked whether the C. kuwanae females had started oviposition.

At the end of all the trials all the coccinellid adults used in the experiment were frozen and dissected to verify sex.

Data were analyzed using a three way analysis of variance (ANOVA) where the effects of 'temperatures' $(\mathrm{DF}=7)$, 'individuals' $(\mathrm{DF}=49)$, 'days' $(\mathrm{DF}=9)$ and interaction 'temperature $\times$ individual' $(\mathrm{DF}=343)$ were examined. The other first order interactions (temperature $x$ days and individual $\times$ days) were pooled in the 'error' since they were of scarce interest and/or of no biological meaning (e.g. it is obvious that a significant interaction 'temperature' $x$ 'days' exists because the temperature was changed every ten days, but this has no biological meaning, simply because it was a condition imposed by the research).

Sources of variation were tested using a pooled error mean square, following Sokal \& Rohlf (1981). The degrees of freedom relative to 'individuals' were also partitioned for 'sex' $(\mathrm{DF}=1)$ and for 'among individuals' $(\mathrm{DF}=48)$ and tested for significance. Duncan's multiple range test was used to verify statistical significance of differences among means.

Correlation coefficients between the recorded characters mentioned above were also worked out.

TABLE 1. Significance of sources of variation for examined characters.

\begin{tabular}{|c|c|c|c|c|c|c|}
\hline \multirow{2}{*}{$\begin{array}{l}\text { Sources } \\
\text { of variation }\end{array}$} & \multicolumn{6}{|c|}{$\mathrm{F}$ values } \\
\hline & $\begin{array}{c}\text { Degrees of } \\
\text { freedom }\end{array}$ & $\begin{array}{c}\text { Holed and } \\
\text { eaten scales (1) }\end{array}$ & $\begin{array}{c}\text { Lifted and } \\
\text { eaten scales }(2)\end{array}$ & $\begin{array}{c}\text { Total number of } \\
\text { eaten scales }(1+2)\end{array}$ & $\begin{array}{c}\text { Number of lifted but } \\
\text { not eaten scales (3) }\end{array}$ & $\begin{array}{c}\text { Total number of eaten and } \\
\text { damaged scales }(1+2+3)\end{array}$ \\
\hline Temperatures & 7 & $172.6 * *$ & $158.1 * *$ & $335.2 * *$ & $52.1 * *$ & $299.0 * *$ \\
\hline Individuals & 49 & $8.6 * *$ & $6.7 * *$ & $11.1 * *$ & $3.0 * *$ & $9.6 * *$ \\
\hline Sex & 1 & $28.1 * *$ & $67.3 * *$ & $96.2 * *$ & $2.3 \mathrm{~ns}$ & $68.1 * *$ \\
\hline Among individuals & 48 & $8.2 * *$ & $5.4 * *$ & $9.9 * *$ & $3.0 * *$ & $8.43 * *$ \\
\hline Days & 9 & $1.4 \mathrm{~ns}$ & $2.4 *$ & $1.3 \mathrm{~ns}$ & $10.2 * *$ & $5.3 * *$ \\
\hline Indivs $\times$ temps & 343 & $3.9 * *$ & $4.0 * *$ & $6.0 * *$ & $2.28 * *$ & $5.6 * *$ \\
\hline Error & 3591 & & & & & \\
\hline
\end{tabular}

ns $=$ not significant; $* *=$ significant for $\mathrm{P} \leq 0.01 ; *$ significant for $\mathrm{P} \leq 0.05$. 


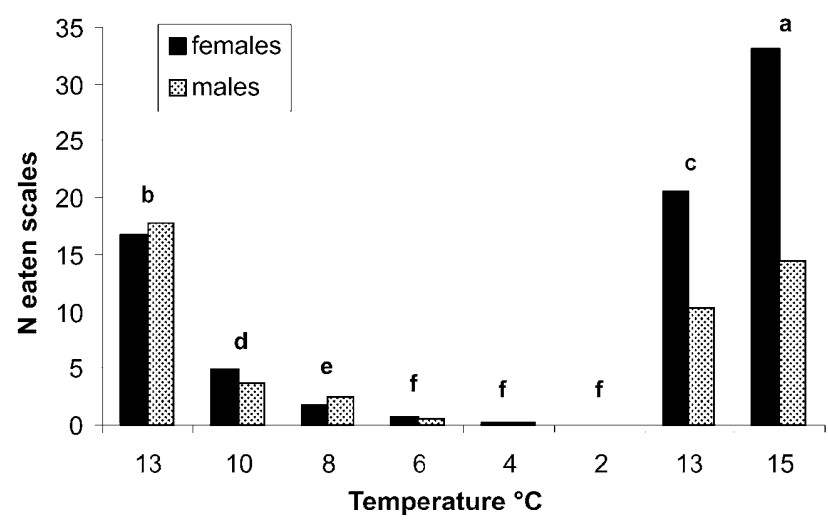

Fig. 1. Total number of scales eaten in ten days for each temperature (averages for twenty-five Chilocorus kuwanae females and males, columns with the same letter are not different for $\mathrm{P} \leq$ $0.01)$.

\section{RESULTS}

In general, the effects of temperature, individual, sex, and day, and the interaction of individuals $\times$ temperature, were all highly significant for the number of scales holed or lifted (and eaten or uneaten) by the predators (Table 1). Exceptions included the effect of 'sex' for lifted but not eaten' scales and 'days' for holed scales and total eaten scales.

Adult predators collected from outdoors adapted quickly to the chamber conditions and trophic activity was evident from the beginning of the experiment.

The total numbers of holed and eaten scales in ten days were significantly and positively correlated with the numbers of lifted and eaten scales over all the experiment $(\mathrm{r}=$ $0.644 ; \mathrm{P} \leq 0.01, \mathrm{DF}=398$ ). For the sake of brevity, only data for total number of scales eaten by both modalities in a ten days period for each temperature (averages over twenty-five $C$. kuwanae females and males respectively) are shown in Fig. 1. The greatest trophic activity was recorded at the final $15^{\circ} \mathrm{C}$ temperature. From the initial $13^{\circ} \mathrm{C}\left(\bar{X}_{13^{\circ} \mathrm{C}}=16.7 \pm 1.68\right.$ and $17.68 \pm 1.39$, for females and males, respectively) there was a sharp decrease in feeding activity until at $4^{\circ}$ and $2^{\circ} \mathrm{C}$ the activity was almost nil. Although consumption was evident at $6^{\circ} \mathrm{C}\left(\bar{X}_{6^{\circ} \mathrm{C}}=0.6\right.$ \pm 0.21 and $0.5 \pm 0.18$, for females and males, respectively), no significant differences were found among the lowest temperatures. When the temperature was raised to $13^{\circ} \mathrm{C}$ the insects resumed feeding and great differences were recorded hence the interaction between sexes, the females with a much higher feeding activity than males. At $15^{\circ} \mathrm{C}$ females ate more than twice the number of scales eaten by males $\left(\bar{X}_{15^{\circ} \mathrm{C}}=33.0 \pm 1.59\right.$ and $14.5 \pm 0.91$, for females and males, respectively).

Fig. 2 shows the number of $U$. euonymi with covers lifted, but not preyed upon in a ten day period for each temperature. Male and female lifting behaviour at all temperatures was the same, (see Table 1); consequently only averages over the fifty individuals are reported. Lifting was greatest at the beginning of the experiment $\left(\bar{X}_{13^{\circ} \mathrm{C}}=\right.$ $7.0 \pm 0.61)$ and then decreased with diminishing tempera-

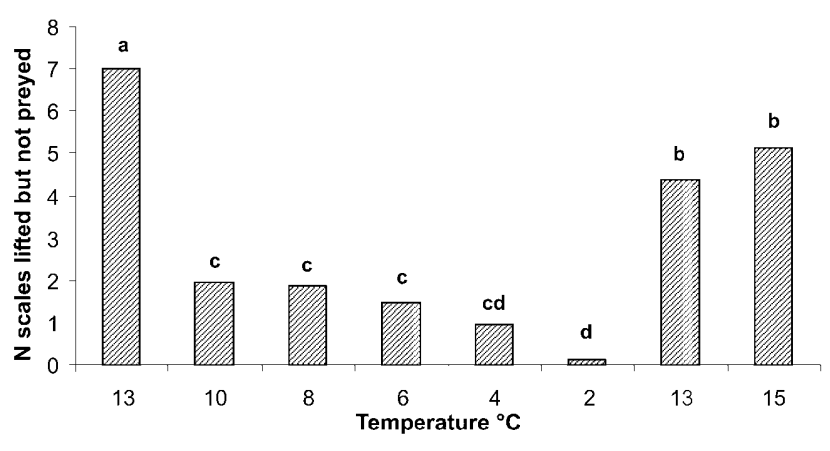

Fig. 2. Total number of scales whose covers were lifted but which were not preyed in ten days for each temperature (averages for the fifty Chilocorus kuwanae individuals, columns with the same letter are not different for $\mathrm{P} \leq 0.01$ ).

tures, although no significant difference was recorded from $10^{\circ}\left(\bar{X}_{10^{\circ} \mathrm{C}}=1.9 \pm 0.21\right)$ to $4{ }^{\circ} \mathrm{C}\left(\bar{X}_{4^{\circ} \mathrm{C}}=1.0 \pm 0.09\right)$. At $2^{\circ} \mathrm{C}$ a few $(12 \%)$ ladybirds were still active $\left(\bar{X}_{2^{\circ} \mathrm{C}}=0.1 \pm\right.$ $0.01)$ and no significant difference was evident from the activity at $4^{\circ} \mathrm{C}$. At $13^{\circ} \mathrm{C}$ ladybird activity rose again, but to lower level than at the initial $13^{\circ} \mathrm{C}$. Activity level did not increase significantly thereafter when the temperature was raised to $15^{\circ} \mathrm{C}\left(\bar{X}_{15^{\circ} \mathrm{C}}=5.1 \pm 0.43\right)$.

The number of scales eaten and the number of scales with covers lifted, but not the number of scales consumed per individual predator, were positively and significantly correlated $(\mathrm{r}=0.676 ; \mathrm{P} \leq 0.01, \mathrm{DF}=398)$. Thus the most active adults not only feed intensely on scales, but are also able to damage them severely by simply removing their covers.

Fig. 3 shows the total number of $U$. euonymi damaged by $C$. kuwanae (i.e. scales holed and eaten plus lifted and eaten plus lifted but not eaten) in a ten day period for each temperature (averages over twenty-five C. kuwanae females and males). The trend in damage across temperatures reveals even more evident differences as temperature decreases than is apparent in Fig. 1. At the initial $13^{\circ} \mathrm{C}$ the number of damaged scales was high, diminishing with decreasing temperatures, but the ladybirds maintained their ability to damage scales until $6^{\circ}-4^{\circ} \mathrm{C}$ (no significant difference was evident between these temperatures). At $6^{\circ} \mathrm{C} \mathrm{C}$. kuwanae females damaged $2.4 \pm 0.51$ scales per day and males damaged $1.7 \pm 0.33$ per day in a ten day period. The ladybird activity was almost nil at $2{ }^{\circ} \mathrm{C}$ and then increased with temperature increase. The coccinellid activity rose to a peak at $15^{\circ} \mathrm{C}$, when the difference between females and males was more than two fold $\left(\bar{X}_{15^{\circ} \mathrm{C}}=40.2 \pm 2.05\right.$ and $17.52 \pm 1.11$ per 10 days, for females and males, respectively).

The range of variation for total damaged scales was very high at the highest temperature $\left(13-15^{\circ} \mathrm{C}\right)$ and in particular for female individuals $(1-75,0-24,0-17,0-11$, $0-6,0-1,1-77$ and 5-94 at 13, 10, 8, 6, 4, 2, 13 and $15^{\circ} \mathrm{C}$, respectively). The coefficients of variation (which gives a measure of variation independent of the mean) relative to females were also very different across temperatures $(93,28,19,20,10,4,67$ and 48\% respectively). This is due to the fact that at the beginning of the experi- 


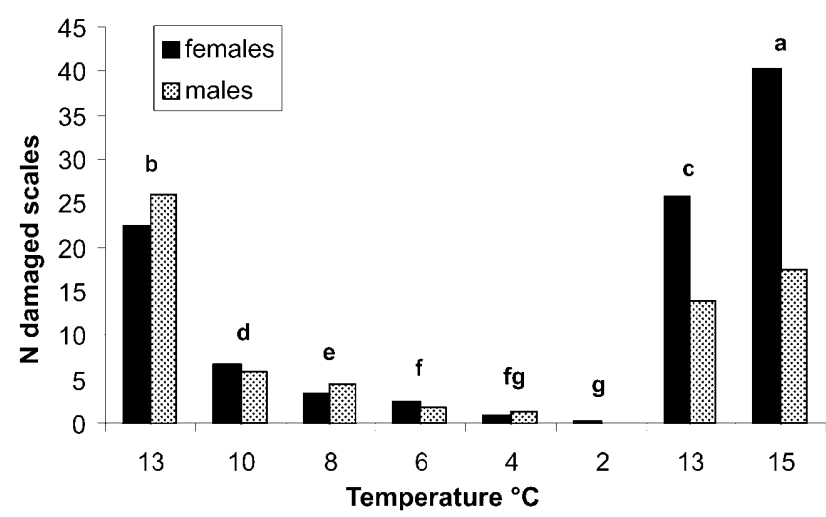

Fig. 3. Total number of damaged scales (combined data for scales holed and eaten, lifted and eaten, lifted but not eaten) in ten days for each temperature (averages for twenty-five Chilocorus kuwanae females and males, columns with the same letter are not different for $\mathrm{P} \leq 0.01$ ).

ment (at $13^{\circ} \mathrm{C}$ ) five females did not eat at all during the ten day period considered and limited their activity to lifting a few scales while all the others fed voraciously on the scales. With decreasing temperatures some females were still active, but behavioural differences were blurred because the low temperatures induced a general quiescence status. As a consequence females were more similar among themselves at lower temperatures than at higher temperatures. However, it is interesting to note that among all the quiescent individuals, six adults (five females and one male) showed predatory activity at least for one day at $2^{\circ} \mathrm{C}$. Raising the temperature to $13^{\circ} \mathrm{C}$ all the individuals, except two males and one female, quickly resumed predatory activity and at $15^{\circ} \mathrm{C}$ all the individuals showed trophic activity.

Variation in predatory activity among individuals of each sex expressed as total damaged scales (i.e. scales holed and eaten plus lifted and eaten plus lifted but not eaten) over the entire 80 days experiment is shown in the frequency histogram in Fig. 4 (7 frequency classes of 30 scales are presented on the abscissa along with the central value for each class, the number of individuals belonging to each class is presented on the ordinate). On average, females damaged more scales than males (101.6 versus 70.7 scales, see arrows). In addition, variability appears to be much greater among females than among males (the range of variation in number of scales damaged is 14-202 and 30-141 for the two sexes, respectively). The significance of 'between sexes' and 'individuals' sources of variation (Table 1) is the result of a more intensive predatory activity of the females which need to increase their body reserves to lay eggs (at $15^{\circ} \mathrm{C}, 60 \%$ of the $C$. kuwanae females laid their eggs).

The significance of 'temperature $\times$ individual' interaction for all the examined characters is also related to the fact that both males and females are included in the 'individual' source of variance and females have different energy requirements. In addition, it is worth recalling that we used a random sample collected in the field so allowing for the inclusion of adults born in different peri-

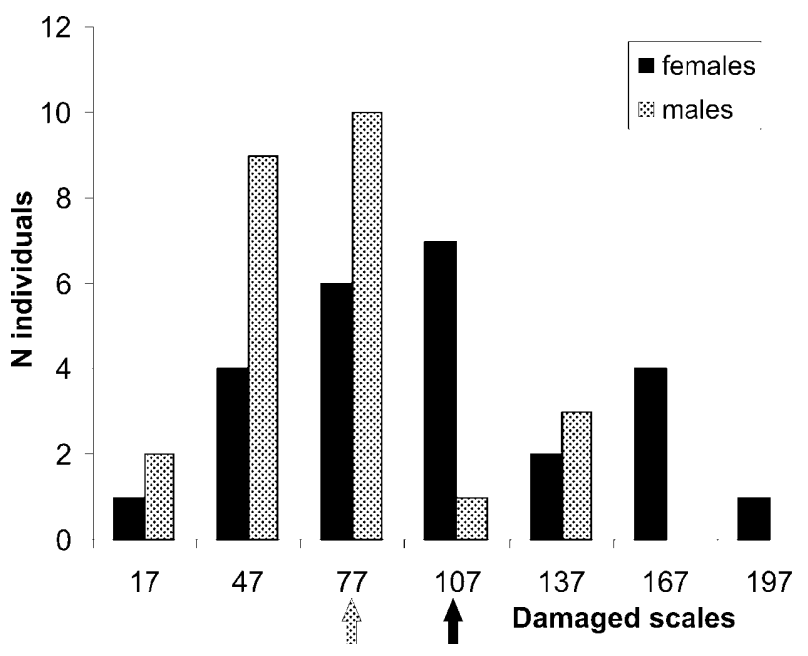

Fig. 4. Frequency distribution for total damaged scales (i.e. scales holed and eaten plus lifted and eaten plus lifted but not eaten) by Chilocorus kuwanae individuals of each sex over 80 days experiment. Numbers on the abscissa are the central value of each class. Arrows indicate the average for each sex.

ods. It is obvious that older adults have a lower energy requirement and eat less than adults born later (see also the note relative to female predatory activity above). However, to assess individual variation for trophic activity was not among the aims of this paper which was only intended to report average data drawn from a wild $C$. kuwanae population close to the winter period.

\section{DISCUSSION}

The Chilocorus spp. are well known predators of various scale insects, in particular hard scales (Diaspididae). Some species, introduced in areas with hot and dry summers for biological control of the scales in citrus groves, did not establish for various reasons among which adverse climatic conditions are most important (Kehat et. al., 1970; Podoler \& Henen, 1983; Hattingh \& Samways, 1994). Podoler \& Henen (1983) showed that C. kuwanae suffered from high temperatures (over $30^{\circ} \mathrm{C}$ ) and adults could die. Our study (with temperatures from $0^{\circ} \mathrm{C}$ to $15^{\circ} \mathrm{C}$ ) complements the work of Podoler \& Henner (1983) in considering the effect of temperature on $C$. kuwanae. Our and their results show that this ladybird is very active when the temperature ranges from $10-22^{\circ} \mathrm{C}$. In addition, we noted that $C$. kuwanae searches for overwintering $U$. euonymi females also at relatively low temperatures and continues to feed at temperatures as low as $2^{\circ} \mathrm{C}$. Below this temperature the ladybird becomes quiescent. When the temperature increases again the ladybird resumes preying on scales. At $15^{\circ} \mathrm{C}, 60 \%$ of females start laying eggs.

Thus C. kuwanae seeks out overwintering females of $U$. euonymi on E. japonicus hedges during mild, sunny winter days, both in their original oriental habitats (Xia et al., 1986 ) and in some north American and central Italian areas where they have been introduced (Drea \& Carlson, 1987; Primavera \& Ricci, 1994). 
The ladybirds emerge from hedge litter and climb up the trunk. They pause to warm themselves and then begin searching for prey. When the temperature begins to drop they descend to the litter. Efficient preying continues through March and April in central Italy with negative repercussions on the spring generation of this scale (unpubl. data).

Given this interesting trophic activity at low temperatures, it would be opportune to release C. kuwanae adults into the E. japonicus hedges in the autumn so that they can prey on overwintering females from autumn to spring. Releasing C. kuwanae in the spring would not produce similar positive effects since this predator is less active in the summer and its populations are reduced by Aprostocetus neglectus Dom., a gregarious Eulophid (Hymenoptera), which parasitizes its larvae (Kuznetsov, 1987; Nohara \& Iwata, 1988; Primavera \& Ricci, 1994).

ACKNOWLEDGEMENTS. The authors are grateful to A. Mommi, C. Dentini, D. Fortini and L. Bartoli for technical assistance. We thank C. Bennett Gillies for editing and revising the English text.

\section{REFERENCES}

Benassy C. 1977: Notas sobre parasites de plagas diaspinas (Chrysomphalus, Lepidosaphes, Unaspis). Biol. Serv. Def. Plagas. Insp. Fitopat. 3: 55-73.

Brewer B.S. \& Olivier A.D. 1987: Euonymus scale Unaspis euonymi (Comstock) (Homoptera: Diaspididae): effects of host cultivar age, and location on infestation levels. J. Entomol. Sci. 22: 119-122.

DREA J.J. \& CARLSON R.W. 1987: The establishment of Chilocorus kuwanae (Coleoptera: Coccinellidae) in eastern United States. Proc. Entomol. Soc. Wash. 89: 821-824.

Driesche R.G. van \& NUNN C. 2003: Status of Euonymus scale in Massachusetts fourteen years after release of Chilocorus kuwanae (Coleoptera: Coccinellidae). Fla Entomol. 86: 383-384.

Driesche R.G. van, Idoine K., Rose M. \& Bryan M. 1998a: Release, establishment and spread of Asian natural enemies of Euonymus scale (Homoptera: Diaspididae) in New England. Fla Entomol. 81: 1-9.

Driesche R.G. van, Kingsley P., Rose M. \& Bryan M. 1998b: Effect of Euonymus scale (Homoptera: Diaspididae) on Euonymus spp. survival in southern New England, with estimates of economic costs of pest damage. Envir. Entomol. 27: 217-220.

Hattingh V. \& Samways M.J. 1994: Physiological and behavioral characteristic of Chilocorus spp. (Coleoptera: Coccinellidae) in the laboratory relative to effectiveness in the field as biocontrol agents. J. Econ. Entomol. 87: 30-38.
Hendrickson R.M., Drea J.J. \& Rose M. 1991: A distribution and establishment program for Chilocorus kuwanae (Silvestri) (Coleoptera: Coccinellidae) in the United States. Proc. Entomol. Soc. Wash. 93: 197-200.

JefFerson D.K. \& Schultz P.B. 1995: Differential susceptibility of six Euonymus species and cultivars to Euonymus scale Unaspis euonymi (Comstock). J. Envir. Hortic. 13: 140-142.

JefFerson D.K., Schultz P.B. \& Bryan M.D. 1995: Distribution of natural enemies of Euonymus scale, Unaspis euonymi (Comstock) in Virginia. J. Entomol. Sci. 30: 273-278.

Kato T. 1968: Predacious behavior of coccidophagous coccinellid, Chilocorus kuwanae Silvestri in the hedge of Euonymus japonicus Thumberg. Kontyu 36: 29-38.

Kehat M., Greenberg S., Gordon D. 1970: Factors causing seasonal decline in Chilocorus bipustulatus L. (Coccinellidae) in citrus groves in Israel. Entomophaga 115: 337-345.

KuzNetsov V. 1987: Chilocorus kuwanae on Sakhalin. Zashch. Rast. (Moskva) No. 9: 44 [in Russian].

Lamdin P.L. 1995: Release, development and establishment of Chilocorus kuwanae Silvestri for control of Unaspis euonymi (Comstock) in Tennessee. Israel J. Entomol. 29: 327-330.

Nalepa C.A., Drea J.J. \& Bryan M.D 1993: Release and establishment of Chilocorus kuwanae (Coleoptera: Coccinellidae) in North Carolina. J. Entomol. Sci. 28: 287-290.

NoHARA K. 1962: On the overwintering of Chilocorus kuwanae Silvestri (Coleoptera: Coccinellidae). Sci. Bull. Fac. Agric. Kyushu Univ. 20: 33-39.

Nohara K. \& Iwata M. 1988: Studies on ovipositing behaviour of Chilocorus kuwanae Silvestri (Coleoptera: Coccinellidae). Proc. Fac. Agric. Kyushu Tokai Univ. 7: 17-24.

Podoler H. \& Henen J. 1983: A comparative study of the effects of constant temperatures on development time and survival of two coccinellid beetles of the genus Chilocorus. Phytoparasitica 11: 167-176.

Primavera A. \& Ricci C. 1994: Note bioetologiche su Chilocorus kuwanae Silvestri (Coleoptera: Coccinellidae), predatore di Unaspis euonymi (Comstock) (Homoptera: Diaspididae). Atti XVII Congr. Naz. Ital. di Entomol. (Udine, June 13-18, 1994). Arti Grafiche Friulane, pp. 609-612.

Ricci C., Garonna A.P., Cappelletti G. \& Viggiani G. 1991: Reintroduzione in Italia di Chilocorus kuwanae Silv. (Coleoptera: Coccinellidae), predatore di cocciniglie. Atti Convegno Lotta Biologica, Acireale (CT), 28 November 1991. pp. 113-121.

Sokal R.R. \& Rohlf F.J. 1981: Biometry. W.H. Freeman, San Francisco, pp. 372-399.

Xia C., Zhang Y. \& Shen B.Y. 1986: Biology of Chilocorus kuwanae and its control of coccids in the field. Chin. J. Biol. Control 2: 70-74.

Received December 8, 2005; revised and accepted February 6, 2006 